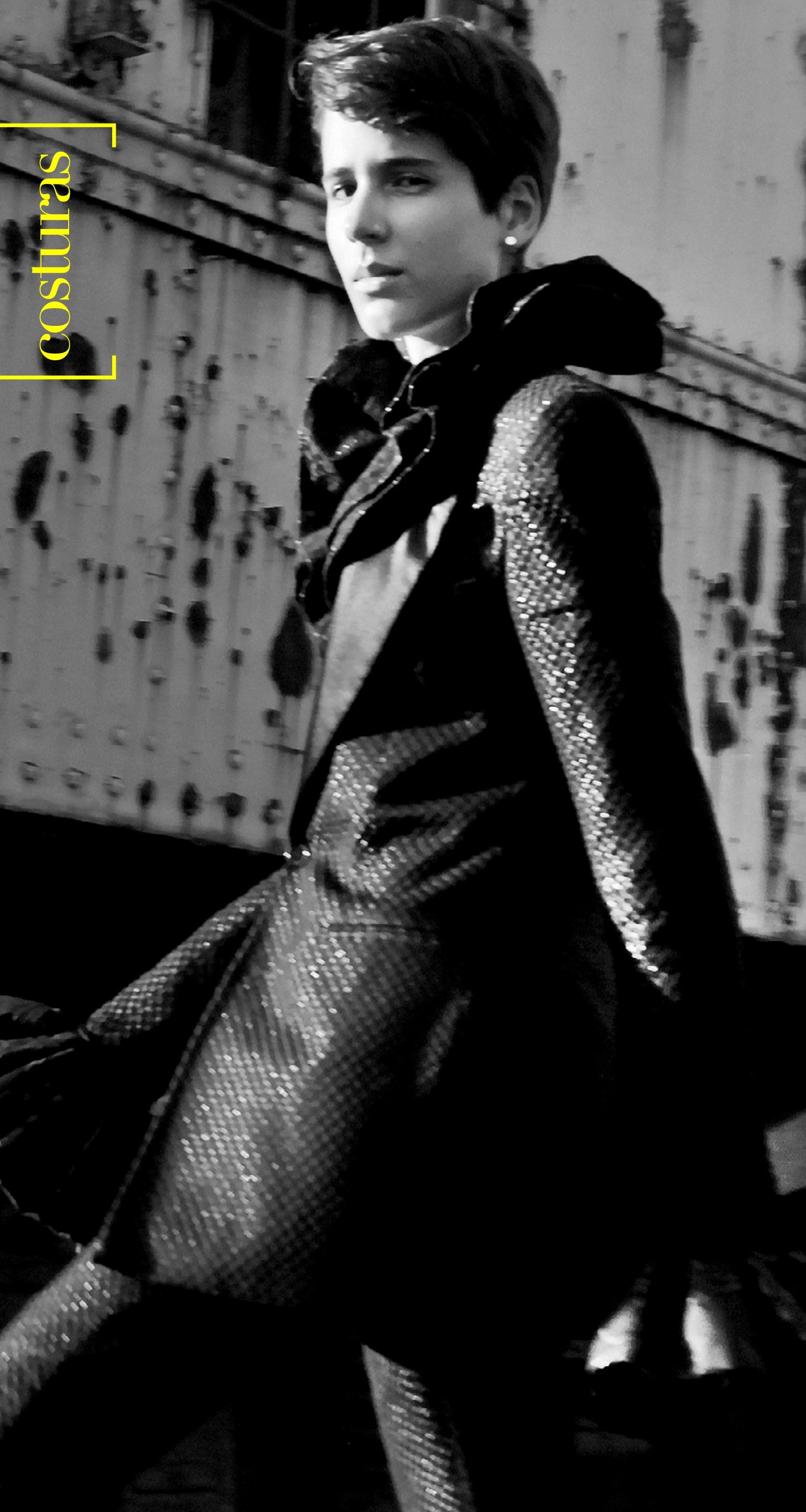




\author{
[ILYA PARKINS $]^{11}$ \\ University of British Columbia \\ E-mail: ilya.parkins@ubc.ca
}

\title{
Territórios de saber e nostalgia na escrita de memória de designers de moda modernos $^{2}$
}


Como Caroline Evans nota em uma discussão sobre as manequins americanas contratadas pelo designer francês Jean Patou em 1924, na moda "o modelo da padronização e a estética industrial eram comumente percebidas como americanas" (EVANS, 2008, p. 250). 0 artigo de Evans (2008, p. 261) traça "tensões na modernidade do início do século XX: entre criatividade e negócio, entre França e América e entre o consumo pela elite e a produção de massa". Ele se apoia no trabalho de Nancy Troy que mostra em seu livro de 2003, Couture Culture, como designers do início do século XX promoviam conceitos de autenticidade em uma batalha frenética para suprimir a lógica interna de cópia e padronização que definia a moda, e como explorar a perceptivel oposição entre França e Estados Unidos era uma estratégia importante nesta batalha. Aqui, eu trabalho a partir dos relevantes insights de Troy (2003) e Evans (2008) para destacar o relacionamento tenso entre França e América nos discursos das casas de moda. Entretanto, eu começo pelas articulações autobiográficas dos próprios designers, pois estas abrem novas dimensões - uma epistemológica e uma intima e psíquica - que nos permitem pensar sobre como o (a) designer está envolvido na manutenção de um discurso de diferenças nacionais - $e_{1}$ ainda, o que o designer pode nos dizer sobre o papel da moda na modernidade.

Os trabalhos autobiográficos dos designers de moda receberam pouquíssima atenção crítica por si só. Provavelmente por causa de suas motivações obviamente comerciais, não foi levado a sério como um documento da subjetividade dos designers. Procurar pelas subjetividades dos designers, no entanto, deixa de lado a maior problemática de suas memórias e autobiografias: que, particularmente na modernidade, a era da massificação da moda em sua presença cada vez mais visivel na cultura, estes textos são indices cruciais das tentativas dos designers de criarem uma persona pública e de assegurarem um legado cultural duradouro. Não importa se escritos ou não pelos próprios designers, não importa o quão estratégicas e potencialmente não autênticas são as expressões de sentimento, estes textos se apresentam como documentos da condição peculiar de celebridades dos designers - e, dessa forma, argumento, eles dialogam com questões maiores sobre o lugar da moda e dos próprios designers na paisagem cultural da modernidade no início do século XX.

De fato, quando lemos a autobiografia de um designer como um documento de autoconstrução da fama, sua relevância para a questão do moderno - tanto para a modernidade cultural quanto industrial - fica clara. A maioria dos designers do início do século XX estava, em algum nível, engajada com a lógica do novo; o sucesso crítico e comercial da moda estava associado ao desejo pela novidade que se alinhava tanto com a determinação das vanguardas culturais frente às inovações em ideias e formas de arte, quanto com a crescente sofisticação tecnológica da produção industrial, que por si já significava um tipo bastante diferente de 
novidade. Como foi demonstrado por uma linhagem de teóricos da moda, indo de Walter Benjamin e passando por Ulrich Lehmann e Caroline Evans, o apego da moda à novidade é um consistente compromisso interno com o passado (e suas assombrações), constantemente reaparecendo em seus ciclos e frequente e explicitamente referenciado na costura. A moda, desta maneira, tem se mostrado, para usar os termos de Walter Benjamin (1999), uma constelação de passado e presente ${ }^{3}$. Claro, isso não era reconhecido explicitamente no início do século XX. No período, as carreiras dos designers eram construídas sobre estes dois alicerces - estética e indústria - da modernidade; 0 sucesso dependia de sua habilidade para se estabelecerem convicentemente como sujeitos modernos, que detinham os segredos da alfaiataria para admitir outros na promessa do moderno. Se obtivessem sucesso o bastante para publicarem memórias e outros escritos autobiográficos, então estas carreiras eram também, por necessidade, exercitadas na produção e manutenção de personas públicas. A carreira de um designer de moda popular no início do século XX, então, era definida por pelo menos duas coisas: o cultivo do novo e a demonstração coerente e convincente deste novo para seus consumidores.

A escrita de memórias dos designers foi um pilar no estabelecimento de uma identidade coerentemente moderna, uma fundação no esforço da criação de "marcas". Mesmo quando publicadas no fim da carreira do designer, escritas autobiográficas cumpriam seu papel em estabelecer o que o crítico Aaron Jaffe (2005) chama de "imprimatur modernista". Em Modernism and the Culture of Celebrity, Jaffe explica esse conceito:

\footnotetext{
Por "imprimatur", quero dizer [...] que o objeto literário modernista sustenta proeminentemente o selo de seu produtor. Ao mesmo tempo uma marca distintiva e uma impressão sancionadora, o imprimatur, como eu o defino, transforma o autor em um artefato formal, fundindo-o ao texto como um sinal concreto de valor (JAFFE, 2005, p. 20).
}

Eu argumento que as autobiografias de designers de moda funcionavam como Jaffe (2005) sugere funcionar o imprimatur modernista: elas permitiam o acúmulo de valor para os designers - mesmo em retrospectiva - com base na percepção de suas individualidades que, por sua vez, vinham de uma noção de suas iconoclastias modernas. Apesar de Jaffe (2005) ter desenvolvido o conceito para falar das particularidades da literatura modernista, vale a pena notar que existe uma relevância especial para o designer de moda, que literalmente cultivava uma particularidade distintiva para indicar a impossibilidade de reprodução da sua arte. Agora, pode ser que as obras autobiográficas dos designers estejam dedicadas à criação de particularidades coerentes. Mas, por mais que tentassem basear seus esforços em criar uma marca para suas costuras com imagens consistentes de personalidade, estas obras expunham as pressões ideológicas 
trazidas como base de suas criações. Atravessadas por tensões e contradições - notavelmente entre uma corrente de conservadorismo que voaria na cara da sensibilidade revolucionária que os designers se preocupavam em articular -, as obras autobiográficas expõem as dificuldades desta produção. Dessa forma, elas também revelam algo do trabalho investido na criação das identidades dos designers. $\mathrm{E}_{1}$ como eu irei indicar aqui, estes escritos - sejam eles um reflexo "genuíno", ou não, do estado psíquico dos designers - expõem algo sobre o posicionamento cultural geral dos costureiros na modernidade.

Uma das camadas de tensão que fica aparente na análise da formação de um imprimatur modernista na escrita autobiográfica de Paul Poiret (ativo entre as décadas de 1900 a 1920) e de Elsa Schiaparelli (ativa do final da década de 1920 a 1950), é a persistente - e constantemente ameaçada - oposição entre o que eu chamaria de duas modernidades diferentes, distinguidas por suas coordenadas geográficas. Os trabalhos parecem testemunhar ansiosamente - mas, de forma crucial, também ajudam a produzir - um conflito entre duas maneiras de ser moderno, dois styles de vie e de orientações estéticas, que eram respectivamente atrelados à França, onde os designers residiram, e à América. Por exemplo, em seu livro de memórias de 1954, Shocking Life, Schiaparelli descreve seu entendimento das ações de tradução cultural necessárias quando ela - por muito tempo residente em Paris, apesar de nascida na Itália - começou uma turnê de palestras nos Estados Unidos durante a Segunda Guerra Mundial. Escreve:

\footnotetext{
A América sempre foi mais do que amigável e acolhedora comigo. Ela tornou possivel para mim obter um lugar único no mundo. A França me deu a inspiração, a América a aprovação gentil e o resultado. Aqui eu tentava dizer para a América... que era impossivel substituir a França no campo de nosso trabalho particularmente criativo. Existem razões impalpáveis que fizeram da França o que ela é... Eu destaquei que a América, a qual deu maravilhosos passos à frente, aplica métodos construídos sobre uma vasta e ilimitada escala de pensamento e produção, enquanto nossos são aqueles de lindos ateliers de pesquisa e fantasia (SCHIAPARELLI, 2007, p.112-113).
}

No trecho, Schiaparelli tem o trabalho de deixar clara sua boa vontade frente aos Estados Unidos. No entanto, mesmo ao expressar sua simpatia pelo pais, ela confia em uma oposição conceitual entre este e a França. Ela alinha a França a um modernismo estético que tem raízes profundas e, até mesmo, trans-históricas, e os Estados Unidos a um ethos de modernização industrial. Isso é, por fim, uma fórmula previsivel, confiando na dicotomização de estética e mercado que vem sendo problematizada nos últimos quinze anos ${ }^{4}$. 
Vinte anos antes, contando sua própria carreira na moda no primeiro de seus três trabalhos autobiográficos, En habillant l'époque (1930) - publicado em inglês como King of Fashion ou My First Fifty Years - o fervoroso crítico anti-Estados Unidos Paul Poiret descreve dessa forma os norte-americanos:

Um americano tem de ver um artigo manufaturado, completo, sólido na sua frente, para que então ele possa copiá-lo servilmente. Sua completa falta de imaginação os previnem de conceber o imprevisivel e o hipotético. Como São Tomás, só acreditam no que conseguem ver. Isso deve restringi-los na ciência e na arte, pois restringiu seu campo de atividade até então (POIRET, 1930, p. 275-276).

Aqui Poiret está desvalorizando os americanos ao chamá-los de empiristas, escravizados por dados concretos. 0 que é fantástico nesse trecho é a invocação de categorias epistemológicas para descrever a oposição entre França e Estados Unidos. Ao abordar a questão dessa maneira, Poiret nos convida a reconsiderar o posicionamento dicotômico das duas nações como uma guerra entre tipos modernos de saber que são concorrentes. Essa abordagem é rica também para analisarmos Schiaparelli: lembrando sua formulação sobre os americanos empregarem "uma vasta e ilimitada escala de pensamento e produção", enquanto os franceses se dedicam à "pesquisa e fantasia", e sua superioridade estética se deveu a "razões impalpáveis". A invocação das escalas situa os métodos americanos de produção espacialmente, enquanto o alinhamento da produção francesa com a fantasia sugere um processo intrigante e, de certa forma, etéreo que, por fim, é impossivel de se conhecer. 0 delinear de um tipo misterioso e desconhecido, particularmente francês, em oposição ao empirismo americano, torna-se então um atalho para a dicotomia da arte transcendente e da indústria vulgar.

Duas coisas são notáveis nessa oposição espacial. A primeira é que, agrupados, Poiret e Schiaparelli encorajam a releitura da França e dos Estados Unidos como epistemes incompatíveis. Suas escritas de memória servem para delinear dois tipos diferentes de saber - 0 ato autobiográfico está, para esses designers, envolvido nas construções de si como tipos específicos de conhecedores (franceses), em oposição àquele conhecedor sugerido pelo empirismo estadunidense. A criação das particularidades modernistas dos designers de moda envolve suas designações como sujeitos de saber. A designação é altamente sugestiva para a concepção do papel tanto da moda quanto dos designers no cenário cultural do início do século XX. Como uma forma que é de uma só vez fantástica e material, efêmera, inconstante e visualmente espetacular, a própria moda necessariamente complica as oposições epistêmicas entre o abstrato e os conhecimentos verificáveis por experiência. A inquieta inconstância dos designers 
para com essa oposição indica a fragilidade da divisão entre a abstração estética e a materialidade do mercado na indústria da moda rapidamente democratizada do século XX.

Trazer uma análise epistêmica destes textos expõe uma segunda dimensão da persona dos designers, que se pode dizer que existe como um contrapeso para as representações fúteis dos designers de moda na mídia de massa nesse período. Os textos delineiam uma melancolia persistente nos dois designers, melancolia esta que baseia e que, é possivel dizer, desaparece através do tom de celebração que cada um traz. Como argumento, essa melancolia se relaciona diretamente com a divisão epistemológica que caracteriza o relacionamento entre Estados Unidos e França; ela emerge do que julgam uma invasão de sucesso da episteme empirista americana sobre a francesa. A aparente morte desta episteme alfineta a retórica progressista e orientada para o futuro, que caracteriza cada trabalho à medida em que a melancolia se transforma em nostalgia, uma modalidade na qual é desenvolvido um personagem melancólico ao se deparar com a inacessibilidade do passado e sua incapacidade de reconciliação com 0 presente (FRITZSCHE, 2001, p. 1592). Uma análise epistemológica destes textos também nos permite entender a melancolia não só como símbolo da condição do designer de moda moderno, mas também tem a potencialidade de jogar uma nova luz sobre a questão da estrutura temporal da moda como uma cristalização surpreendente do passado e do presente.

Apesar de Poiret e Schiaparelli serem dois designers muito distintos, escrevendo em épocas levemente distintas, uma leitura comparada de seus trabalhos autobiográficos gera revelações importantes que nos permitem generalizar sobre a condição do designer de moda na modernidade. $\mathrm{Na}$ verdade, é precisamente o caráter divergente de seus escritos de memória que faz uma análise comparativa ser tão efetiva. 0 tom de seus trabalhos difere substancialmente. As três obras autobiográficas de Poiret, En habillant l'époque (1930), Revenez-y (1932) e Art et phynance (1934), podem ser muito bem descritas como reabilitações defensivas da própria fama do designer, lançadas como foram, ao fim da última e conturbada década da carreira de Poiret e no fracasso de seu negócio. Os trabalhos de Poiret são, também, convencionais em sua retórica e estrutura; são narrativas cronológicas que colocam o autor e sua filosofia estética, sem dúvida, como centrais, e podem ser lidas como apelos retóricos para uma identidade coerente. 0 único trabalho autobiográfico de Schiaparelli, Shocking Life (2007), apesar de também ser uma narrativa cronológica, não oferece 0 mesmo tipo de estrutura aparentemente direta. Do contrário, é caracterizada pelo que Caroline Evans (1999, p. 23) chama de "uma tendência ao faz-de-conta...um divertido jogo de quebra-cabeças, cheio de mecanismos de distanciamento que servem para destacar a natureza contingente e precária da identidade". Então, em um nível, o trabalho de Schiaparelli contrasta intensamente com o de Poiret. Consequentemente, é ainda mais 
notável perceber que, de suas abordagens divergentes, emerge um conjunto análogo de preocupações epistemológicas e temporais. É por essa razão, eu afirmo, que os dois textos podem ser usados juntos para, com cautela, teorizar sobre o estado da persona pública do designer moderno e podem, também, nos dizer algo sobre os valores psíquicos da moda como uma indústria cultural.

Para compreender a maneira como o território e a epistemologia estão conectados nestes textos, começo analisando mais de perto como o conhecimento é mapeado pelo espaço. Uma das características mais notáveis da autobiografia de Schiaparelli $(2007$, p. 9) é seu alinhamento constante ao etéreo; ela diz "continuar a acreditar nos milagres" e se caracteriza como uma "mística" que "não conseguiria se curvar às leis da religião". Sua "crença", diz ela, "estava diretamente conectada com a origem da harmonia e da criação, mas ela "não conseguiria se forçar a passar pelos canais dos homens" (SCHIAPARELLI, 2007, p. 20). Aqui ela estabelece sua inclinação antimaterialista, demonstrando um desejo de abalar as estruturas físicas e convencionais que a sufocavam. Para uma designer de moda - cuja carreira era, necessariamente, construída sobre sua dominação dos materiais - essa constante invocação do além-matéria como base de seu caráter é reveladora. Pode-se discutir que as roupas que ela desenhava, de fato, sustentavam essa tensão entre material e imaterial, já que sua obra é famosa por suas características de surrealismo e a incorporação de princípios de incerteza que atraem o espectador como conhecedor profundamente incerto. Schiaparelli traz um resumo direto perto do fim de seu livro dizendo que ela tem uma forte crença no desconhecido e que, ao fim de sua carreira, ela estava em contato mais profundo com o além - de fato, isso é o que a impulsionou para a aposentadoria. 0 além é o meio com o qual ela torna espacial - ou talvez, mais precisamente, não-espacial - o desconhecido que tanto preza. À medida em que sua carreira chega ao seu fechamento e ela publica suas considerações sobre sua vida e obra, ela revela um certo desespero para transcender os parâmetros do tempo e do espaço.

A escrita autobiográfica de Poiret realiza movimentos similares contra o comércio, invocando um tipo de não-lugar impossivel de ser localizado como o reino artístico dentro do qual ele se propõe estar. Para ele, isso se manifestava frequentemente como sonho ou imaginação, os quais, ele nota em Art et Phynance, são - apesar de "irreais" - possiveis por conta de sua capacidade deteriorada de engendrar o espaço convencional da realidade. Aqui, ele se pergunta qual é mais poderoso, realidade ou sonho, e responde: "Acho que o sonho é mais poderoso, porque ele engendra a realidade" (POIRET, 1934, p. 21). Isso concede um poder constitutivo ao imaterial, ao não situado, que efetivamente privilegia o não-lugar sobre 0 espaço convencional. A tendência em privilegiar essa categoria de Lugar Nenhum é desenvolvida por toda sua escrita, geralmente tomando a forma de uma preocupação clássica com a beleza eterna que, por sua vez, tenta 
alinhar o princípio estético no qual seu trabalho se funda com um valor cultural que é considerado transcendente de tempo e espaço.

0 que é curioso sobre essa invocação de um Lugar Nenhum como princípio governador de ambos estes textos é o constante compromisso com a falta do lugar. 0 Lugar Nenhum é, por definição, impossivel de se localizar, claro, mesmo quando os designers frequentemente o situam na terra, localizado na França. Minimamente, a França é, em virtude de ser a antítese dos Estados Unidos, uma importante facilitadora ou habilitadora dos valores do não situado que eles tanto prezam. Ao se localizarem neste espaço não-situado, que é indireta e intermitentemente alinhado com as possibilidades estéticas representadas pela França, Schiaparelli e Poiret são capazes de se distinguir da topologia material dos Estados Unidos, dando forma aos seus trabalhos através de descrições de cidades, palcos de palestras, lojas e fábricas - com efeito, através de representações da materialidade da nação. 0 que chama a atenção no grande trabalho de cada autor é a natureza mundana nas descrições dos Estados Unidos da América, opostas às descrições de lugares na França, esta última sendo associada aos locais únicos dos ateliês, das casas e das exposições dos designers. Os espaços franceses são privilegiados e, também, semitranscendentes devido a suas relações com os designers, mediadores do desconhecido. Os lugares americanos, orientados no sentido dos espetáculos fúteis e vulgares de consumo e produção, são, por contraste, fatalmente reais, inexoravelmente materiais. Eles são conhecidos com transparência, enquanto que os tipos de conhecimento que devem ser facilitados pela geografia ainda não totalmente descrita da França são incertos, não materiais e, por fim, instáveis.

0 que nos deve dar alguma interrupção no trabalho dos dois designers é uma estranha, intermitente, atribuição de transcendência espacial aos Estados Unidos da América, o que já notei anteriormente. Isso às vezes parece comprometer sua insistência na diferença epistêmica entre eles mesmos e os americanos. Lembrem-se que Schiaparelli (2007) descreve a "vasta e ilimitada escala de pensamento e produção" na América, contrastando-a com o francês "atelier de pesquisa e fantasia". Poiret também aponta essa vastidão, alinhando-a com uma certa monumentalidade: "seus conceitos são mais vastos e mais monumentais que os nossos" (POIRET, 1931, p. 270). Uma espécie de falta de limites é posta em jogo aqui, mas o apego da América ao mundo da produção industrial baseada em objetos a diferencia da profunda transcendência material dos franceses. De fato, a figuração da vastidão e da transcendência deriva do tamanho das paisagens americanas - são amarradas ao espaço - e por este motivo não representam uma transcendência para o além. 0 além valorizado por Poiret e Schiaparelli não possui correlação espacial.

Eu gostaria de sugerir que este mote contrastante estabelece ambos efetivamente como praticantes de uma espécie de modernismo transcendente, emergindo de um plano não-situado de livre movimento. Ele desmaterializa 
os designers e os trabalhos com os quais eles se engajam enquanto artistas e industrialistas modernos. Há, claramente, algo libertador nesse tipo de leveza e parece se tornar um refúgio da modernidade, mesmo quando conjurado no nome da experimentação modernista. No período moderno, a moda e seus mundos parecem, por vezes, dialogar indiretamente com o desejo de vários modernistas por uma válvula de escape das pressões da modernidade. No caso de Poiret e Schiaparelli, que sustentam o peso desta tensão entre arte e comércio, isso é um escape para a liquidez que oferece descanso desta tensão, ainda que ajude também a ancorar a estruturação de suas marcas como tipos únicos de sujeito. 0 movimento de desterritorializar, então, os constrói como sujeitos, constrói suas casas com o apropriado legado de transcendência e arte e oferece a eles a dissolução subjetiva como um remédio para o espirito moderno sobrecarregado.

Ao fazer este movimento de distanciamento do espaço, Schiaparelli e Poiret estão sugerindo algo sobre o conteúdo e o valor do saber e a construção do conhecedor na França. Mas, com mais importância, eles estão também apontando para um conhecedor francês específico da indústria da moda. 0 repúdio à espacialidade é, necessariamente, ao processo de produção sobre o qual seus negócios se sustentam. As recusas em localizarem a si próprios e suas formas de saber - trianguladas com a criatividade e a imaginação - efetuam um apagamento do processo de produção que remete ao fetichismo da mercadoria. 0 fetichismo da mercadoria - que envolve, na clássica formulação de Marx, obscurecer ou apagar o processo de produção da mercadoria para que o objeto receba a aura mágica - é certamente um argumento óbvio em qualquer discussão de moda. Mas, aqui, ele se torna visivel de um jeito diferente. 0 que é perceptivel é que o que está sendo apagado aqui não são necessariamente as condições de produção do objeto - no caso da indústria da moda, as roupas -, mas as condições de produção do saber (francês e dos sujeitos epistêmicos franceses); nesse caso, as condições de emergência dos designers, já que os designers se tornam as mercadorias. Julie Rak (2002) nota que, no mercado de massa da escrita de memória, apesar do sucesso do trabalhar depender na representação de um sujeito coerente, "o desenvolver de uma subjetividade narrativa no texto significa que o sujeito escritor da autobiografia deve se tornar um objeto para que sua identidade seja embalada para consumo" (RAK, 2002, p. 155). Nestes textos autobiográficos, o estabelecimento de epistemes em competição é um ingrediente central para o desenvolvimento de uma persona pública vendável para os designers.

Porque, é claro, alguém compra as mercadorias. Se o sujeito da autobiografia é uma mercadoria, é este sujeito objetificado que o consumidor está comprando. Em seus não-lugares, os designers representativos do saber francês oferecem ao consumidor a promessa do acesso - através da compra - a uma forma de saber e, por extensão, a uma forma de vida. 0 que é digno de nota nestes textos é que eles revelam o engajamento na 
construção das marcas, na divulgação dos designers e de suas casas em diversos níveis: especialmente por conta das casas não estarem mais em funcionamento, o que se promove através da construção dos designers como tipos específicos de sujeitos epistêmicos é um ponto de vista epistemológico. A moda moderna se torna nítida como uma maneira de preservar, ou talvez germinar, uma forma de saber cuja existência parece ser ameaçada pelas mesmas condições de produção industrial que a definiam cada vez mais. E, como nos mostram as escritas de memórias, os designers chegam a personificar essa tensão. Suas publicações, tão rapidamente descartadas como meros devaneios para o mercado de massa, parecem sustentar os traços deste encontro entre epistemes em competição e isso carrega o trabalho com a qualidade melancólica que decola frente aos seus propósitos e aos esforços do clamor público ligados a eles.

Reconhecer a qualidade melancólica das autorrepresentações dos designers nos leva a atentar ao tipo de narrativa que é contada nestas obras, sobre seus relacionamentos mutáveis com a América como epistemes incompativeis com as próprias. Ambos os textos são caracterizados pela manifestação de uma certa esperança em relação à América, a qual eventualmente se transforma em uma decepção com o empirismo e a indústria americana. Em seu texto, Schiaparelli apresenta isso bem cedo, sugerindo que sua primeira viagem à América, uma década antes de começar a desenhar roupas, a trouxe violentamente para a realidade de uma fantasia otimista sobre as possibilidades americanas: "América, o sonho mágico do mundo, sustenta expectativas além do que pode ser realizado humanamente" (SCHIAPARELLI, 2007, p. 28). Todas as descrições dos Estados Unidos feitas por Schiaparelli depois carregam a marca inicial de sua decepção. Com suas descrições feitas no tempo de exílio neste país, durante a Segunda Guerra Mundial, a decepção adquire uma aura melancólica. Quanto mais tempo ela passa na América através do curso de sua carreira, mais fortemente ela se localiza como um tipo diferente de conhecedora daquilo que aparentemente é produzido e privilegiado pelos americanos. A transformação sugerida da imagem da América como um local de magia e esperança funciona como um tipo particular de narrativa do conhecimento nostálgico, lamentando a perda da naiveté, a inocência infantil, e estrategicamente opondo Schiaparelli a essa naiveté.

Poiret faz um movimento similar, senão ainda mais explícito, mas o faz através de uma atribuição nostálgica desta naiveté diretamente aos americanos. Ele argumenta que o único francês capaz de entender a psique americana é "o garoto da escola primária" (POIRET, 1931, p. 279), um empirista inocente que pode navegar pelo massacre esmagador de dados sensoriais que a América representa com suas multidões, sua arquitetura, sua cultura visual frenética. Esta imagem é carregada com um tipo de privilégio epistêmico que os franceses não têm. Em uma passagem particularmente digna de nota, Poiret escreve sobre os franceses: "a maneira de 
nossa educação nem sempre nos facilita o entendimento da massa deste povo. Do contrário, ela nos debilita, e nossa bagagem de conhecimento, cultura e riqueza nos restringe assim que damos partida nesta estrada" para os estados Unidos (POIRET,1931, p. 179). Aqui, então, o empirismo da América é equacionado à falta de educação.

Logo, tanto Poiret quanto Schiaparelli utilizam a categoria de conhecimento inocente ou ignorante. Apesar de seus posicionamentos a respeito desta naiveté serem divergentes, a valorização geralmente nostálgica desta categoria e sua associação com o empirismo americano também contribuem para estabelecer a ambos como conhecedores mundanos e entediados com o mundo. Esse aparente elogio à promessa de conhecimento americano se torna um comentário a respeito da sofisticação do designer e a difamação da sensibilidade americana.

De fato, a figuração do desconhecer e do mistério como cruzes a serem heroicamente carregadas pelos designers de moda franceses, em face do massacre da cultura de consumo americana, é forte nestes textos. Eu ainda discutiria sua função como tema central em ambos relatos. Em ambos textos, a representação da arte melancólica é enraizada no valor dos designers, como sujeitos epistêmicos em extinção. $E$, se tomamos essa escrita de memória como um estudo na construção retroativa de uma persona pública, como a construção de um legado - como devemos considerar, segundo os textos publicados no fim das carreiras dos designers - então precisamos levar em conta qual é o significado do investimento dos designers em se compreenderem como oferendas heroicas e sacrificiais, na construção da relação entre epistemes modernas e competitivas, que eles sabem, já que escrevem relatos em retrospectiva, que uma será vitoriosa.

Todos sabem que a América sai vitoriosa no jogo em que estavam envolvidos. Poiret lutou uma guerra contra a cópia e a reprodução não-licenciada, que era, de certa maneira, uma guerra contra a América. Como Troy (2003) aponta em Couture Culture, o final de sua carreira foi marcado por tentativas em encontrar um meio termo entre a indústria americana e a imaginação francesa. Sua incapacidade em retomar a sua glória pré-guerra nos anos 1920 é detalhada em Art et phynance (1934), uma memória inteiramente dedicada a descrever a dissolução de seu negócio e marcada por uma raiva mal disfarçada dos financiadores que o enganaram enquanto ele tentava se reconstruir. No fim, a Casa de Poiret faliu, mesmo enquanto ele dava seu nome à linha prêt-à-porter aparentemente americanizada que tanto desprezou. Seu fracasso parece dar conta do tom amargo de sua obra autobiográfica; a melancolia que domina suas tentativas em salvar seu legado da banalização na década de 1920 até o início de 1930 se origina do reconhecimento de que era incapaz de retardar as forças do empirismo americano. 
Schiaparelli, de sua parte, assistiu à mudança da vanguarda da moda pós Segunda Guerra Mundial, a perda da supremacia parisiense para a força manufatureira americana. Ela conta isso em um tom melancólico. Nas páginas finais de Shocking Life, descreve sua decisão de se aposentar em 1954:

Eu sabia que para construir com mais solidez é preciso, às vezes, destruir. Que se deve aprender a entender a língua do povo que não conhece a diferença entre o bife e a carne, e ao mesmo tempo ajudar a construir uma nova elegância de maneiras e roupas, uma nova aristocracia, adequada para coordenar com o ritmo cru da vida moderna (SCHIAPARELLI, 2007, p. 207).

0 relato de Schiaparelli difere do de Poiret. Ela é mais circunspecta e menos amarga sobre a necessidade de encontrar um meio termo entre as epistemes americanas e francesas e seus modos de produção, talvez por nunca ter passado as dificuldades que Poiret passou com seu negócio, pois, pelo contrário, escolheu se aposentar enquanto ainda tinha sucesso. Mesmo assim este trecho evidencia um reconhecimento de que ela também falhou, ainda que menos espetacularmente que Poiret. Ela escolhe um tom seguramente otimista - afinal, quer "construir com mais solidez" os domínios da moda e do estilo - mas reconhece que a episteme francesa foi, por enquanto, eliminada pelo estilo americano.

Então, essas autobiografias não oferecem somente um relato da competição entre as epistemes, mas as suas dissoluções. Em ambos os textos há um deslize: os Estados Unidos da América vão de ser representados como uma nação de empiristas desastrados, mas bondosos, para uma entidade ameaçadora e monstruosa. No texto de Schiaparelli, isso é evidente em sua descrição do exilio na América durante a Segunda Guerra. Ela diz (referindo a si mesma na terceira pessoa, como faz intermitentemente através do texto), "algo estava errado. Uma força maligna estava agindo contra Schiap, apesar de ela não saber de onde vinha. Agora mesmo, neste mundo desmontado, tudo que Schiap fez foi destruído ou agredido por uma mão invisivel de um demônio" (SCHIAPARELLI, 2007, p.145). Os Estados Unidos vêm aqui representar o mal (e é interessante notar, como observação, como de certa forma o desconhecido é transfigurado, revelado dessa vez com uma aparência americana, mas tomado de um aspecto demoníaco muito diferente do desconhecido francês). A representação de Poiret da monstruosidade americana é diferente; ele cria a personificação do grotesco, por exemplo, dos americanos como "um Gargântua, com cem braços e vinte milhões de bocas, todas abertas sobre o mesmo continente" (POIRET, 1931, p. 279). Tal imagem obviamente pede a simpatia do leitor pelo designer conflituoso e, ainda, sustenta seus autorretratos nos termos iconoclásticos e heroicos. 0 triunfo de uma episteme norte-americana que é monstruosa em sua escala e mecanização se apresenta ainda como outra 
oportunidade de ancorar, retroativamente, o modernismo transcendente dos designers e de assegurar seus legados.

A narrativa de invasão, no entanto, também estabelece os designers como sujeitos nostálgicos. Ao alinharem a América com a modernidade industrial, contrária a uma espécie de modernidade trans-histórica - um tempo moderno que, apesar de tudo, é marcado por suas raizes profundas em tradições estéticas e intelectuais anteriores - os autores sugerem que esse passado foi sobreposto, perdido. A nostalgia em si é uma confusão temporal, como a teorização de Peter Fritzsche (2001) sobre o aumento da nostalgia ao fim da Revolução Francesa deixa claro; ela é feita possível por uma "reconfiguração mais larga da temporalidade" caracterizada por conceitos de "descontinuidade histórica e periodicidade histórica" que constroem o passado como inacessivel e outro ao momento presente (FRITZSCHE, 2001, p. 1588). Como explica Fritzsche, em outra passagem.

Enquanto a nostalgia tem o passado como seu objeto lúgubre, ela o mantém afastado. As belezas do passado são queridas e seu fim lamentado, mas não há dúvida de que elas não são mais recuperáveis. Em outras palavras, a nostalgia se constitui pelo que não pode possuir e se define por sua incapacidade de se aproximar de seu objeto, um paradoxo que é essencial da melancolia nostálgica (FRITZSCHE, 2001, p. 1595).

0 conceito de Fritzsche (2001) da melancolia nostálgica também estabelece os valores epistemológicos da nostalgia: com a emergência dos entendimentos de ruptura histórica e descontinuidade, "o passado se transforma em um problema de conhecimento e se torna uma fonte de inquietudes, uma irritação, presença incontrolável de falta" (FRITZSCHE, 2001, p.1588). A nostalgia evidencia a interpretação subjetiva do passado. Questiona, como se sabe, o que não era presente, mas era "inacessivel e encarcerado" (FRITZSCHE, 2001, p. 1592), mesmo que tenha continuado a viver na memória pessoal e na própria constituição do self. A nostalgia é a reflexão da inserção do self, modernamente, na época histórica, para que então a história seja personalizada, tome uma dimensão íntima. Para Fritzsche, essa estrutura temporal única está na raiz da proliferação da memória e da autobiografia no período moderno (FRITZSCHE, 2001, p. 1608).

A discussão de Fritzsche (2001) sobre a melancolia nostálgica identifica essa consciência temporal única na proliferação das narrativas de perda e desapropriação, as quais traçam as negociações subjetivas de traumas e eventos históricos de larga escala. Apesar de estar tratando da primeira metade do século XIX, sua teoria a respeito dessas histórias de exílio e desapropriação como indícios da internalização de uma consciência histórica mutável na modernidade fornecem um meio intrigante com o qual se pode entender as autobiografias de moda de Poiret e Schiaparelli. Contrariando 
a estudada e intermitentemente alegre excentricidade dos autorretratos de Schiaparelli, contrariando o tom enaltecedor daqueles de Poiret, estas obras podem ser lidas como relatos de perda e desapropriação. E, considerando seus contextos - o mundo moderno da moda, baseado e dependente como era da constante reinvenção do novo - este sentido de perda nos diz algo a respeito do propósito de suas escritas de memórias e de suas relações com a indústria da moda em geral.

Em minha introdução, destaquei o conceito de Aaron Jaffe (2005) do imprimatur modernista, do qual emerge a celebridade literária moderna como marca. Mobilizar a ideia do imprimatur modernista como uma particularidade coerente ou uma marca pessoal é útil para os estudos da moda, apesar de certamente diferir do modo como é usado no modernismo literário. 0 modernismo literário era um domínio no qual as discussões sobre dinheiro e mercado eram abertamente desencorajadas, enquanto que a indústria da moda era alimentada por elas. De qualquer maneira, a noção de imprimatur adquire uma aura intrigante quando o modernista em questão está escrevendo para estabelecer, em retrospectiva, uma identidade coerente, para impor, no fim de suas carreiras, uma particularidade a si mesmos. Qual é, para ser direta, o motivo de se estabelecer uma identidade coerente, relativa à marca, se não há nenhum ganho material - se, como aconteceu com ambos os designers, o negócio em questão está acabado? 302 Não há dúvidas de que ao menos uma parte da equação é o ganho material - e isso é especialmente verdade para Poiret, que encontrou problemas financeiros sérios em seu período pós-carreira, quando publicou estas suas três autobiografias. 0 fato de que Schiaparelli publicou sua obra imediatamente após o fim de sua Casa - quando ela não estava enfrentando dificuldades financeiras significativas - e que Poiret, obsessivamente, publicou não uma, mas três autobiografias, sugere que há algo em jogo além do lucro na escrita que, por fim, consolidou o imprimatur modernista. Se as bases de Fritzsche no que diz respeito à nostalgia como um sintoma moderno de perda e desapropriação forem verdade, então torna-se possivel ler estas obras como testemunhas da perda representada por uma cultura globalizante, que se caracteriza pelas epistemes múltiplas, aparentemente incompativeis. Frente à essa perda, o recontar de suas carreiras recebe uma aura muito específica; estas obras podem ser lidas como esforços para fixar e memorizar não só eles mesmos, mas também uma maneira de saber. Ao fim de sua autobiografia, Schiaparelli deixa claro que, ao se aposentar da indústria da moda, ela havia se submetido à lógica do novo que definia a moda e sua modernidade; ela devia "fazer uma mudança drástica" (SCHIAPARELLI, 2007, p. 207). Ela fornece uma pista do que está em jogo nessa submissão quando escreve que, ao se aposentar,

Eu devo não só me libertar da bagagem excessiva de posses e inveja, mas eu devo também me libertar das amarras do amor e da devoção. Isso significou lágrimas e alivios, significou apertar 
meu próprio coração sem piedade; não deve haver nenhuma leveza, nem arrependimentos (SCHIAPARELLI, 2007, p. 207).

Schiaparelli sugere que a desistência era dolorosa o bastante para necessitar coragem emocional. A maior obra de Poiret, King of Fashion (1931), termina em um tom similar. Ele relata a dissolução de sua Casa em termos estranhamente pouco detalhados, depois de descrever sua ascensão com detalhes ricos: "Foi o fim de tudo. Alguns dias depois eu fui transformado em uma companhia limitada. Todos sabem o resto da história" (POIRET, 1931 p. 330). Aqui seu laconismo emocionado também atesta que o triunfo da episteme americana - que é, em sua cabeça, a causa de sua queda - é doloroso demais para se debruçar sobre por muito tempo. Tanto Poiret quanto Schiaparelli erguem defesas psíquicas contra o sentimento de perda que se origina de suas noções de que um modo de saber foi superado e, com seu fim, suas próprias noções de si são ameaçadas.

A questão da noção dos designers sobre suas próprias identidades começa a revelar para nós a importação deste legado textual da melancolia e da perda. Ela enfatiza o que está em jogo nestas autobiografias para aqueles interessados na relação da moda no início do século XX com estruturas mais amplas da modernidade. As obras revelam o ponto intimo de intersecção entre a compreensão de Poiret e de Schiaparelli sobre múltiplos regimes de conhecimento, e seus posicionamentos ambíguos de si mesmos como sujeitos modernos de um tipo muito particular - artistas-industrialistas. Os esforços de Poiret e Schiaparelli em se fixarem na memória como sujeitos epistêmicos apontam para ansiedades - sobre a relação entre arte e comércio, entre o original e a cópia, a elite e o mercado de massa - que são intrínsecas ao desenvolvimento da indústria da moda no início do século XX. Mas eu sugiro que isto demonstra algo mais sobre essa ansiedade, pois o trabalho autorrepresentacional revela sua dimensão subjetiva e melancólica. Apesar de ser importante lembrar que estas são memórias comercializadas em massa, claramente escritas com o objetivo de assegurar um legado para a Casa de moda como uma marca, elas parecem sustentar os traços de uma insatisfação melancólica. Proponho que esta melancolia é uma grande condição da modernidade para o designer de moda francês. $E$, além disso, que emerge de uma contradição que eles vivem entre um modernismo transcendente com bases trans-históricas e uma modernidade industrial, que ameaça não apenas ofuscar suas perceptíveis singularidades, autenticidades e mestrias, mas torná-los obsoletos como sujeitos. Não posso deixar de recordar a batalha arquetípica entre a modernização e o modernismo cultural, que foi demonstrada por estudos recentes da crítica modernista como uma dicotomia falsa, mas que certamente se manteve ideologicamente atraente; era uma tensão extremamente real para pessoas como Poiret e Schiaparelli e seus públicos. Esses designers podem, penso, serem lidos como inauguradores desta tensão entre arte e comércio. E é a moda que os coloca lá, com suas promessas simultâneas de distinção 
cultural e massificação ideológica. Neste sentido, penso que as memórias de moda nos apontam para o caminho em que os valores ideológicos da moda, como uma modalidade geral do moderno, podem ser internalizados pelos designers. Como Caroline Evans nota em outro contexto, "a moda, com sua afinidade pela transformação, pode encenar a instabilidade e a perda" (EVANS, 2003, p. 6) como narrativas fundadoras do moderno. A moda materializa essas modalidades, mas ela em si não nos permite acesso como experiências subjetivas. Instabilidade e perda são o que encontramos nas escritas de memória de Poiret e Schiaparelli e isso levanta a questão dos valores psíquicos da operação de diferentes paradigmas epistemológicos - e suas relações com a moda.

A questão do conteúdo emocional e ressonância de duas epistemes diferentes e aparentemente nacionalizadas importa porque destaca a especificidade da moda. Obviamente, a moda em si sustenta a contradição entre arte e comércio. Em seus escritos, os designers subjetivaram este encontro tenso. A questão não é se esta angústia é "autêntica" ou não. A questão é que esta é outra maneira pela qual a representação e a realidade da moda são amarradas ao imaginário moderno, sempre à beira da devastação. Gilles Lipovetsky escreve em The Empire of Fashion que a moda "pacifica o conflito social, mas acentua o conflito do sujeito e entre sujeitos: permite mais liberdade individual, mas gera um maior mal-estar na vida" (LIPO304 ] VETSKY, 1994, p. 241), e o faz ao acentuar as divisas entre atores sociais, rompendo as conexões entre si, exacerbando as divisões caracteristicas da modernidade como vividas na metrópole. Não são apenas os que vestem e consomem a moda que vivenciam suas qualidades alienantes. Estas obras dos designers nos mostram como eles, também - em seu sustento das contradições da moda - são tocados pela relação profunda entre moda e alienação. Lipovetsky (1994) e Caroline Evans (2003) discutiram que privilégios de moda ressaltam a profundidade da anomia moderna. E também, eu adicionaria que, por ser uma modalidade tão pessoal e incorporada, nos aponta para as dimensões intimas da experiência desta anomia. As obras de Poiret e Schiaparelli nos apontam para essa dimensão psíquica e sua conexão com a questão das modernidades em competição - uma empírica ou industrial, a outra desconhecida, criativa - e as maneiras como podem enriquecer nossos entendimentos da melancolia relacionada à moda para os sujeitos em geral.

Por fim, o que é intrigante nas dimensões melancólicas destes textos é a maneira pela qual eles contribuem para a contínua teorização das constelações passadas e presentes da moda, as quais citei anteriormente. Desde Benjamin - aliás, discutivelmente, desde Baudelaire - 0 aparente caos do envolvimento do passado no presente da moda tem sido território rico para seus teóricos. Ao mostrar aos leitores como essa complexidade temporal nasceu para os designers modernos, em nostalgia, a escrita de memória deixa clara a permanência desta construção e, mais importante, 
seu significado pessoal para os sujeitos associados a moda. Nestas obras, o problema aparentemente filosófico da temporalidade se transforma em uma questão de saber subjetivo, uma experiência vivida de dissonância. 0 que é mais útil é a maneira com a qual eles materializam e personalizam as reconfigurações temporais da modernidade, que tão frequentemente são lidas como abstratas e impessoais. Isto é instrutivo para que pensemos a moda, já que a moda também funciona como uma união íntima entre 0 corpo e o mundo, ligando sujeitos individuais, de carne e osso, a movimentos de massa. Como Ann Rosalind Jones e Peter Stallybrass colocam em seu livro sobre a figuração da moda no início do período moderno, "as roupas são mundos vestíveis: um mundo de relações sociais colocado sobre o corpo daquele que as veste" (JONES; STALLYBRASS, 2000, p. 3). 0 trabalho autobiográfico de designers modernos começa a ilustrar para nós a maneira como este "mundo vestível" é mediado e experienciado pelos sujeitos que proveram os materiais, no período moderno, para serem vestidos. 


\section{NOTAS}

${ }^{1}$ Artigo traduzido por Matheus Hotz - hotzmths@gmail.com

${ }^{2}$ Esta é uma versão em português do artigo "Territories of Knowledge and Nostalgia in Modern Fashion Designer Life Writing", originalmente publicado em Fashi"on in Popular Culture: Literature, Media and Contemporary Studies, edição organizada por Joseph Hancock, Vicki Karaminas e Toni Johnson-Woods (London: Intellect, 2013, p. 103-20). "Territories of Knowledge [...]", por sua vez, é uma versão atualizada de "Early Twentiethcentury fashion designer life writing", publicado na CLCWEB: Comparative literature and culture (Purdue University, v. 13, p. 1-10, 2011), e está disponivel em <http://dx.doi.org/10.7771/1481-4374.1711>.

${ }^{3}$ Ver também Lehman (2000), Evans (2003) e Vinken (2005).

${ }^{4}$ Ver Jensen (1993), Dettmar e Watt (1996), Burns (1996), Turner (2003) e Jaffe (2005).

\section{REFERÊNCIAS}

BENJAMIN, Water. The Arcades Project. Tradução Howard Eiland e Kevin McLaughlin. Cambridge: Belknap Press, 1999.

BURNS, Susan. Inventing the Modern Artist: Art and Culture in Gilded Age America. New Haven: Yale University Press, 1996.

DETTMAR, Kevin; WATT, Stephen (Org.). Marketing Modernism: Self-Promotion, Canonization, and Re-Reading. Ann Arbor: University of Michigan Press, 1996.

EVANS, Caroline. Masks, Mirrors and Mannequins: Elsa Schiaparelli and the Decentered Subject. Fashion Theory, v. 3, n.1, p. 3-32, 1999. Press, 2003.

Fashion at the Edge: Spectacle, Modernity, and Deathliness. New Haven: Yale University

. Jean Patou's American Mannequins: Early Fashion Shows and Modernism. Modernism/ Modernity, v. 15, n. 2, p. 243-263, 2008.

FRITZSCHE, Peter. Specters of History: On Nostalgia, Exile, and Modernity. The American Historical Review, v. 106, n. 5, p. 1587-1618, 2001.

JAFFE, Aaron. Modernism and the Culture of Celebrity. Cambridge: Cambridge University Press, 2005.

JENSEN, Robert. Marketing Modernism in Fin-de-Siècle Europe. Princeton: Princeton University Press, 1993.

JONES, Ann Rosalind; STALLYBRASS, Peter. Worn Worlds: Renaissance Clothing and the Materials of Memory. Cambridge: Cambridge University Press, 2000.

LEHMAN, Ulrich. Tigersprung: Fashion in Modernity. Cambridge: MIT Press, 2000.

LIPOVETSKY, Gilles. The Empire of Fashion: Dressing Modern Democracy. Tradução Catherine Porter. Princeton: Princeton University Press, 1994.

POIRET, Paul. En habillant l'époque. Paris: Grasset, 1930. 1931

. King of Fashion. Tradução Stephen Haden Guest. Philadelphia, London: J. B. Lippincott,

Revenez-y. Paris: Gallimard, 1932.

. Art et phynance. Paris: Lutetia, 1934

RAK, Julie. Autobiography and Production: The Case of Conrad Black. International Journal of Canadian Studies, n. 25, p. 149-168, 2002.

SCHIAPARELL, Elsa. Shocking Life: The Autobiography of Elsa Schiaparelli. London: VEtA Publications, 2007 [1954].

TROY, Nancy J. Couture Culture: A Study in Modern Art and Fashion. Cambridge: MIT Press, 2003.

TURNER, Catherine. Marketing Modernism between the Two World Wars. Amherst: University of Massachusetts Press, 2003.

VINKEN, Barbara. Fashion Zeitgeist: Trends and Cycles in the Fashion System. Tradução Mark Hewson. Oxford: Berg, 2005. 